\title{
Responses to child sacrifice in Uganda
}

\author{
Peter K. Byansi ${ }^{1}$, Agatha Kafuko ${ }^{2}$, Anselm Wandega ${ }^{3}$, Paul Bukuluki ${ }^{2, *}$ \\ ${ }^{1}$ School of Health Sciences, Nkozi University, Uganda \\ ${ }^{2}$ Department of Social Work and Social Administration, School of Social Sciences, \\ Makerere University, Kampala, Uganda \\ ${ }^{3}$ ANPPCAN, Uganda Chapter, Kampala, Uganda \\ *E-mail address: pbukuluki@ss.mak.ac.ug
}

\begin{abstract}
This paper reflects on the various interventions and responses that were mounted in response to the problem of child sacrifice. The paper asks and seeks answers to three basic questions: What were the civil society and government responses to the problem of child sacrifice? How were the civil society and government interventions implemented, coordinated, funded, and monitored? How adequate and sustainable were the interventions initiated?
\end{abstract}

Keywords: Child protection; service delivery; child sacrifice; interventions

\section{INTRODUCTION}

The most recent study on child sacrifice in Uganda showed that a child is mutilated every week (Fellows, 2013). The phenomenon of child sacrifice came to the limelight in the late 1990s when the first reports of the practice appeared in the local media (Annie, 2009; Jubilee Campaign \& Kyampisi Child Care Ministries, 2011). In 2008, when the Uganda Police released a crime report indicating that ritual murders involving mainly children had risen by over $800 \%$ from the previous year - rising from three to twenty five - policy makers and parents alike were alarmed and outraged (Bukuluki, 2009). From then on, panic and fear gripped the country with parents and guardians fearing that their children would be the next target.

The fear was heightened by media reports which indicated a growing number of housemaids, parents, and relatives involved in sacrificing children or selling them to ritual murderers and human organ traffickers in order to become rich. Parents did not know whom to trust anymore. The fear that child sacrifice was gaining ground as a ritual, as a means of getting and sustaining riches, and as a business for human organ traffickers raised a lot of concern and stimulated action among stakeholders. In the period between 2009 and 2011, parents, communities, government, religious leaders, traditional healers, local and international Non-government Organizations civil society organizations started organizing themselves to respond to the growing problem of child sacrifice.

This paper reflects on the various interventions and responses that were mounted in response to the problem of child sacrifice. The paper asks and seeks answers to three basic questions: What were the civil society and government responses to the problem of child 
sacrifice? How were the civil society and government interventions implemented, coordinated, funded, and monitored? How adequate and sustainable were the interventions initiated?

\section{METHODS}

In order to get answers to the above questions and understand the nature and scope of the responses that were undertaken, we utilized several methods and approaches. First, we conducted a literature search on interventions on child sacrifice in Uganda. We located the literature using "Google" and "Yahoo" search engines; databases such as Psychological literature (PsychLit), Sociological Abstracts, Academic Search Complete, and the tables of contents of journals and books. Second, we searched websites and publication lists for organisations and government departments implementing family and child-related programs such as Ministry of Gender, Labour and Social Development, National Council for Children, Ministry of Education, Family Life Network, Action Aid International, Uganda Child Rights NGO Network (UCRNN), UNICEF, Save the Children, World Vision, Plan International, and African Network for Prevention and Protection against Child Abuse and Neglect (ANPPCAN). The literature had to meet the following criteria: (a) discussing child sacrifice in Uganda, (b) discussing initiatives (i.e., medical as well as the psychosocial and economic interventions) aimed at preventing child sacrifice and enabling survivors to cope with and overcome the trauma associated with it (c) discussing the various actors addressing child sacrifice especially those with programmes targeting traditional healers that are often accused of orchestrating child sacrifice.

Our search for published journal articles and books on child sacrifice in Uganda yielded only one article by Pat Caplan: 'Child sacrifice' in Uganda? The BBC, 'witch doctors' and anthropologists. It also revealed one firsthand account research report entitled: Child Sacrifice and Mutilation of children in Uganda and one book entitled Saving Little Viola, which is authored by Oscar Ranzo. The book is currently being used by Lively Minds, a Nongovernment organization, to increase awareness and prevent child sacrifice.Others child sacrifice-related articles were mainly in the print media. The local print media with articles on child sacrifice included The New Vision, The Daily Monitor, The Observer, Red Pepper, Bukedde, Lupiny, Etop, Orumuri, Gwanga, The Sunrise, and The East African. The international media included the British Broadcasting Corporation (BBC), The Observer, UK, M2 Presswire, Coventry, UK; Cape Times, Cape Town, South Africa; Toronto Star, Ontario, Canada; Herald Sun with Chapel Hill Herald, Durham, North Carolina; Associated Press, Xinhua News Agency and BBC Monitoring Africa, London, UK.

Third, we contacted organizations implementing community development projects targeting children and traditional healers for reports and case studies on child sacrifice. Fourth, we participated in stakeholder meetings discussing child sacrifice. Lastly, we interviewed various key informants - in the Police Force, Ministry of Gender, Labour, and Social Development, local and International Non-government Organizations (NGOs) to gain insights into what is being done in relation to child sacrifice.

This chapter presents the findings from this process. We begin by presenting the various actors in the fight against child Sacrifice. We then present the interventions undertaken by different actors to address the growing problem of child sacrifice. We conclude with a discussion of existing gaps in interventions and key recommendations. 


\section{1. What is Child Sacrifice?}

Fellows (2013: 8) defined child sacrifice as (sic), "the harmful practice of removing a child's body parts, blood or tissue while the child is alive". Fellows also noted that individuals sacrifice and mutilate children for reasons ranging from the need to prevent and overcome illness, gaining wealth, and appeasing ancestors, to determining the sex of a child. The firsthand accounts of detailed in Fellow's study indicate that child sacrifice is prevalent yet not well understood and poorly addressed by government, especially the police. This observation notwithstanding, this chapter attempts to piece out and highlight what various actors have done or still doing to address child sacrifice in Uganda.

\section{2. Main actors in the fight against Child Sacrifice}

Available information shows that the main actors in the fight against child sacrifice included: local and international NGOs, bilateral partners, and the government through the police, Ministry of Gender, Labour and Social Development, and Ministry of Education. It also shows that intervening organizations designed and independently implemented anti-child sacrifice activities and/or participated in the NGO anti-child sacrifice coalition that was coordinated by ANNPCAN.

Other entities, for example UNICEF, funded and supported research, planning, and advocacy efforts aimed at informing anti-child sacrifice programming and policy formulation. The key local and international organizations that initiated anti-child sacrifice interventions or participated in various NGO coalition activities included: Action Aid International, Plan International, Save the Children, World Vision, African Network for Prevention and Protection against Child Abuse and Neglect (ANPPCAN), Lively Minds, Uganda Human Rights Commission, Gideon Foundation against Child Sacrifice, Budukiro Child Foundation, Save Street Children Uganda, Kyampisi Child Ministries, Jubilee Campaign, Joy for Children, Human Rights Network (HURINET), Uganda Law Society Legal Aid Project, and Safe World for Women ( Bells, 2011; Caplan, 2010; Safe World for Women, undated; Straziuso, 2010; UNPPCAN, 2009).

Other actors included religious leaders, and traditional healers who initiated various awareness raising activities independently and through their umbrella organizations ${ }^{1}$. The electronic and print media put a spotlight on the problem of child sacrifice and provided useful information to parents, teachers, and policy makers on what drives the vice and what should be done to protect children. The United States Government supported the Uganda police force with equipment worth 15,000 United States dollars to help prevent and stop child sacrifice and human trafficking (Anonymous, 2009). It also trained the police to better detect, arrest, investigate and prosecute child sacrifice and human trafficking suspects.

\section{3. Interventions addressing Child Sacrifice}

Available information shows that dealing with child sacrifice remains a challenging issue for all those in the field and for society as a whole. This is because child sacrifice is a brisk crime undertaken in secret and is driven by structural drivers such as poverty,

\footnotetext{
${ }^{1}$ These were: the Inter Religious Council of Uganda, which brings together the major faith groups in Uganda (i.e., Muslims, Catholics, Protestants, Seventh Day Adventists, and Orthodox) and Traditional and Modern Health Practitioners together against AIDS and Other Diseases (THETA), National Council of Traditional Healers and Herbalists (NACOTHA) and Promotion of Traditional Medicine in Uganda (PROMETRA), which work with traditional healers in Uganda
} 
unemployment, food insecurity, lack of a regulatory framework for traditional healers, and inadequate mechanisms for child protection at the community and family levels, and sociocultural beliefs and practices that are difficult to change in a short time (Bukuluki, 2009; Fellows, 2013). At the peak of the problem of child sacrifice in Uganda, the interventions which were established to deal with it can be categorized under three broad areas: Prevention, Case Management or response and Capacity Building. Some actors implemented only prevention interventions while others undertook both prevention and case management/ response activities. Others undertook only capacity building initiatives. Table 1 indicates the various organizations that were involved in the drive against child sacrifice and the types of interventions they implemented.

\section{4. Prevention Interventions}

Child Sacrifice prevention interventions included: Awareness raising campaigns or information sharing, policy research and Advocacy.

\section{Awareness Raising Campaigns and Information Sharing:}

The campaign against child sacrifice relied largely on local print and electronic media, community dialogues, and integration of discussions of child sacrifice in other community level activities; for example, in religious sermons, school assemblies, and community meetings. The main aim of all these awareness activities was to inform the public especially parents and guardians and schools about the drivers of child sacrifice and what they could do to prevent it and support the affected children and families. The community dialogues which were conducted by civil society organizations had a triple purpose: to generate communitylevel perspectives on the drivers of child sacrifice; discuss and agree on communityappropriate strategies for preventing child sacrifice and ensuring child protection; and create awareness about the problem.

The integration of child sacrifice discussions in other community-level activities, the use of community dialogues, and the electronic and print media campaigns broaden public knowledge on child sacrifice and influence people's attitudes, opinions, and behaviour towards witchcraft. The media played and continues to play an important role in creating awareness and mobilizing action on child sacrifice. Community dialogues and discussion of child sacrifice during other community activities such as school assemblies and community meetings enabled people to ask questions in order to understand who is behind child sacrifice, its drivers and what they could do to avert it. Between 2007 and 2009, the New Vision reported 38 incidents of child sacrifice. Such reports and graphic descriptions and depictions of child sacrifice were responsible for the mobilization of public anger against child sacrifice (Jubilee Campaign and Kyampisi Child Care Ministries, 2011). The media played a significant role in forming and influencing public attitudes, opinions, and responses to child sacrifice.

Although the government and civil society organizations used the media to increase awareness and cause action on child sacrifice, some key informants observed that the media was double-faced. On one hand, the media portrayed some "traditional healers" as being behind the spate of child murders and witchcraft yet on the other it continued to show Nigerian movies showing cases of rugs to riches as a result of ritual murders (see also Okwori, 2003). The media also advertises the services of many traditional healers that are not registered under THETA, NACOTHA, or PROMETRA, the umbrella bodies that seek to positively influence the activities of traditional healers. Some participants in child sacrifice 
advocacy meetings observed that this double-faced nature of the media may have caused confusion among the public and inhibited some community members to react appropriately.

To most individuals, there is a thin line between witchcraft and traditional healing. The public has limited understanding of the difference between a traditional healer and a witchdoctor. To the public, some of the individuals that were implicated in witchcraft and child sacrifice were once regarded as traditional healers that were providing herbal remedies and socio-cultural solutions to people's problems. This raised questions such as: what makes a person a traditional healer or witchdoctor?;does a witchdoctor only become so if he or she does something that causes harm to people but remains a traditional healer if he or she does things people regard to be good? Providing answers to these questions is outside the scope of this article but those interested in learning about the differences and similarities can consult with Simon Fellows work (2013).

These misgiving about the media notwithstanding, existing evidence shows that the media is critical in forming and influencing people's attitudes and behaviour, placing child protection issues on the public and political agenda and provides opportunities for reaching multitudes of people in a short time (Saunders \& Goddard, 2002).

Undeniably, the combination of community-level awareness activities and the use of media during the anti-child sacrifice campaigns in Uganda is credited with reaching multitudes of people and making parents, schools and communities more vigilant in monitoring the movements and interactions of children with strangers and suspicious relatives in the community and at school. Children became cautious in dealing with strangers and in responding to negative peer pressure. They also became adept at reporting suspicious persons to the parents, local council leaders and the police. This had the effect of making would-be child murderers and abductors feel that they were being watched, which may have contributed the decline in the reported cases of child sacrifice.

Although other writers acknowledge the positive contributions of the media to child protection they also observe that it can create a "climate of fear, mistrust, and blame" which may impact child protection (Ayre, 2001: 887). For instance, individuals may not share useful child abuse information because they fear making headlines that would jeopardize their social relationships and livelihoods. Some may relate with others with suspicion and mistrust, which may prevent genuinely focusing on the child protection. This often results in individual and organizations focusing on protecting their images as opposed to the child protection agenda. Some key informants observed that the media attention that was accorded to child sacrifice could have contributed to making some traditional healers and other people to commit child murders in order to become famous or cause fear in the public. Others argued that it could have made others make false claims about child sacrifice in order to become famous or gain reputation. Some cited the self-confessed child murderer reported by the BBC program (see Caplan, 2010), News Night, as one typical case of an individual seeking to become famous or divert the public from focusing on the real criminals. Ayre (2001) recommends that before dealing with the media, organizations should seek to understand it and what creates news in order to avoid inadvertently jeopardizing the child protection agenda. Critical analysis of Fellows' (2013) findings shows that the problem of child sacrifice is real and still prevalent in Uganda. The study's findings suggest that the media neither exaggerated nor sought to scare people but highlighted a growing and serious community problem. 


\section{Policy Research and Advocacy:}

Although child sacrifice was being reported in the media, few individuals and organizations had a clear understanding of why it was happening, the individuals by behind it and the community-appropriate interventions for addressing it. In view of this, child-focused organizations undertook some rapid assessments in order to understand the nature and scope of child sacrifice. In particular, the Ministry of Gender, Labor, and Social Development with funding from UNICEF undertook a rapid assessment of child sacrifice in Uganda. The resultant assessment report provided useful information on the nature and extent of child sacrifice in Uganda and what communities believed were the most appropriate approaches to dealing with the problem. It also informed the development of a National Action Plan to address the Problem of Child Sacrifice.

Although prior to the production of the assessment report and action plan, different organizations, particularly NGOs, religious bodies, and media were engaged in anti-child sacrifice efforts, either independently or as coalitions, to bring about social and political change and to prevent child sacrifice, the interventions lacked solid evidence. Key informants noted that the assessment report increased awareness about the problem of child sacrifice, and provided civil society organization with key evidence that they needed to bolster their activism against child sacrifice.

The most evident advocacy effort was "the human sacrifice campaign" which was conducted in the form of a coalition, spearheaded by ANPPCAN Uganda Chapter, a child rights national NGO. In 2009, ANPPCAN mobilized different stakeholders in a coalition to conduct a campaign against Child Sacrifice, under the theme 'Working together to restore Human Dignity and Value for Life'. Traditional healers through one of the leading associations, Promotion of Traditional Medicine in Uganda (PROMETRA) were a part of the steering committee that planned, coordinated and implemented this campaign. ANPPCAN considered working with traditional healers as a strategy, which would make this campaign more effective. The media was a key partner in this campaign. The aims of the campaign were: (i) to pressure government to adopt a policy regulating the conduct of traditional healers; (ii) to demystify the beliefs surrounding Human Sacrifice by holding open dialogues on the subject; (iii) to show support and a willingness to help those affected and; (iv) to show a commitment against this practice. The national parliament, the ministry of Justice and Constitutional Affairs were the primary targets of this campaign. The public at large was also a target audience and actor in this intervention. Lobbying, media advocacy and social mobilization were used in combination as the key advocacy tools.

Media coverage was important to increase the profile given to child sacrifice, to reach decision makers and to increase public action against child sacrifice. Press conferences were organized where journalists were given information to familiarize them with issues related to child sacrifice. The campaign included television and radio clips where persons who were considered influential, such as religious leaders from Muslim and Christian backgrounds, traditional healers, business men, artists, opposition politicians featured denouncing child sacrifice.

Advocacy efforts included presentations to members of parliament, meetings, phone calls and emails were utilized to influence government officials to focus on child sacrifice and develop punitive laws. Children were mobilized to relay messages to parents and policy makers. Children met with members of parliament and presented a statement to MPs, echoing the message of campaign organizers.

In relation to social mobilization, information materials such as posters, stickers, $t$-shirts were produced and distributed. A public dialogue on child sacrifice was organized where 
issues related to child sacrifice were presented, and the public given an opportunity to discuss these issues openly. The media covered these processes and relayed the outcomes of such discussions to the wider public. A march through the capital city was also organized. The organizers of the campaign considered this as a key activity, which would demonstrate to those in favour of child sacrifice that this practice was not going to be tolerated.

A constructive approach, as opposed to an adversarial one was adopted by the campaign. Although firm demands were made on the authorities, the campaign movers worked closely with government departments particularly police. This advocacy campaign pressurized the authorities to develop, implement and improve policies to curb child sacrifice. In particular demands were made towards regulation of traditional healers, repealing the Witchcraft Act of 1957, establishment of special courts to address child sacrifice, formation of an independent entity to coordinate child sacrifice responses, and increased funding to police to improve their capacity to investigate child sacrifice. The constructive approach, the credibility of actors, the ability to mobilize public officials, as well as relations with the media contributed to keeping the issue of child sacrifice on the public agenda.

Through these advocacy efforts, the Prevention in Trafficking of Persons Act (2009) was enacted. This has been hailed as a groundbreaking legislation with regard to child sacrifice. The Act subsumes human sacrifice under aggravated trafficking and provides a comprehensive definition of trafficking in children, which caters for the use of children in rituals. The Act criminalizes trafficking and associated consequences such as sacrifice. The Act sets out clear terms measures for protection, assistance and support for victims of trafficking. Within this particular provision, the act identifies a range of services which victims of are entitled to. The Act also provides for the designation of an office to ensure coordination, monitoring and oversight of implementation of the act.

\subsection{Case management and Response}

After the 2008 Police report on ritual murders, the response to child sacrifice was swift. The government and civil society organizations came together and mounted a serious and coordinated response, albeit within limits of inadequate resources and information. The Ministry of Gender, Labour, and Social Development and Uganda Police coordinated the government response while ANNPCAN coordinated the civil society response. Government constituted a commission of inquiry to investigate child sacrifice. The commission of inquiry was deemed necessary in order to generate understanding of the nature and scope problem, upon which government would take action. It is worth noting that the results of the inquiry have never been made public.

Civil society actors responded by undertaking psychosocial and medical interventions, which included counseling for survivors and their families, home and hospital visits for survivors, reconstruction surgery and formation of community-based child protection committees. For example, Save the Children working with local partners in Northern Uganda formed child protection committees, which were responsible for the protection of children from violence and abuse. Lively Minds, ANPPCAN, and Kyampisi Childcare Ministries supported survivors to access reconstruction surgery and treatment in hospitals and clinics. In addition to providing counseling to survivors, ANPPCAN supported formal education for survivors and enabled their families to undertake livelihood interventions aimed at reducing their vulnerability to child sacrifice. Support for education and livelihood activities was seen as a long-term strategy for addressing the structural drivers of child sacrifice - poverty, food insecurity, and unemployment. 
Actors such as FIDA, ANPPCAN, World Vision, Kyampisi Child Care Ministries, and the Uganda Law Society through its legal aid project also sought to increase access to justice by documenting cases, supporting investigation of cases and legal representation of survivors and affected families (Caplan, 2010; Jubilee Campaign \& Kyampisi Child Care Ministries, 2011). The Uganda Police in fulfillment of its responsibility of investigating offences related to child sacrifice was instrumental in arresting, investigating, and providing useful information to courts and legal officer to aid access to justice. Through these efforts some convictions of culprits have been made (See Jubilee Campaign \& Kyampisi Child Care Ministries, 2011). One of the big successes registered in this regard was in March 2011, when a witchdoctor was handed a 50-year sentence for committing child sacrifice (ibid).

In response to the growing phenomenon of child sacrifice, the Inspector General of Police set up a 15-member Anti-Trafficking and Human Sacrifice Task Force at the national and district levels (Bukuluki, 2009). The aim of the task force is to improve the investigative capacity of police with regard to human trafficking and sacrifice related offenses. The task force is mandated to monitor, coordinate and spearhead intelligence, investigations and public sensitization on handling human trafficking and sacrifice. The focus of the task force is to prevent human trafficking and sacrifice through enhanced timely detection, public sensitization and effective investigations. The task force is active at the national level and enjoys the support of development partners such as USAID and has close links with NGOs working against child sacrifice such as ANPPCAN. However, Bukuluki (2009) reported that at the district level, police officers seconded to the task force are not aware of their specific roles and responsibilities. The rapid assessment on child sacrifice found that these police officers were not been oriented and adequately trained to take on their new roles under this task force.

The Ministry of Education responded by encouraging schools to engage with and advise parents and communities to initiate, support, strengthen, and sustain child protection measures. In response, some schools developed measures to increase protection for children as they travel to and from school. For most rural and isolated schools, children are advised to move in groups as they travel to or from school. Some schools adjusted arrival and departure time so that children do not arrive before 8:00am or leave school after 5:00pm and children were advised against accepting lifts in cars or on motorbikes from strangers (Nkhonjera, 2009).

At the family level, parents and guardians responded by cautioning housemaids against opening for visitors, including workers of utility companies such as National Water and UMEME and extended family relatives without their express permission (Nkhonjera, 2009). Feeling that justice was not being done to the perpetrators of child sacrifice, some communities reacted by lynching suspects including those held by police (Fellows, 2013).

The Ministry of Gender, Labour and Social Development with funding from UNICEF and working closely with the National Council for Children and civil society organizations developed a National Plan of Action against Child Sacrifice. The Action plan has four strategic objectives, namely: (i) to increase action towards prevention and further occurrence of child sacrifice; (ii) to improve the scale, quality and capacity of investigation, law enforcement and prosecution of cases of child sacrifice; (iii) to effectively respond to the physical, psychosocial and medical needs of victims/survivors of child sacrifice and their families; and (iv) to build a knowledge base on child sacrifice and related activities through scientific research. 


\section{6. Capacity Building Interventions}

Capacity building interventions involved building the capacity of existing structures to respond to the problem of child sacrifice. Notable among these initiatives was the support by UNICEF for the Ministry of Gender, Labour, and Social Development in undertaking a rapid assessment on child sacrifice and in developing an action plan to combat such harmful traditional practices through the use of communication for social change, better police for prevention and support for child sacrifice survivors and witnesses. The other capacity building initiatives by UNICEF included: providing both technical support to health and law enforcement authorities and civil society organizations to provide prevention, case management and response services; working with a consortium of agencies to set up a hotline for reporting missing children and other forms of gross child rights violation; and supporting civil society organizations led by ANPPCAN Uganda Chapter, Plan International and the Uganda Child Rights NGO Network (UCRNN) to develop a multimedia campaign to address key child protection issues ${ }^{2}$.

The U.S. Government not only provided funding to the police task force on child sacrifice but also oriented them in using effective approaches to arrest, investigate, and prosecute child sacrifice and human trafficking suspects. Lively Minds using the book Saving Little Viola conducts participatory workshops in Primary Schools workshops where the author and social worker read for pupils stories highlighting the dangers of ritual murder.

It equips them with skills they can use to protect themselves against child sacrifice. Schools are provided with copies of the book (Saving Little Viola) and posters, which reinforce learning long after the workshops, are over. The Teachers are trained to run similar workshops as a strategy for ensuring the continuity and sustainability of the programme. An in-school competition is run, to sustain and enhance interest in the materials and child protection.

\section{7. Existing Gaps}

Although much was done in response to wave of child sacrifice incidents that were reported in various parts of the country, most of the interventions were short-term in nature. This is understandable given the nature of the crisis at the time - children were being sacrificed and stopping the vice required such short-term measures. Nonetheless, the momentum against child sacrifice seems to have reduced.

Though a number of projects such as Sustainable Comprehensive Response (SCORE) for vulnerable children and their families and the strengthening the Ugandan National Response for Implementation of Services for OVC (SUNRISEOVC), which have a focus on child protection, are currently being implemented in Uganda, they are not specifically oriented toward addressing child sacrifice.

Furthermore, despite the presence of a police task force, the capacity of police to investigate cases related to child sacrifice remains questionable. One of the highly publicized sacrifice cases, which included a businessman, and a 12-year-old child, ended in an acquittal due to insufficient evidence. Presiding judge derided the police for failure to provide evidence in this case. Though an appeal was made and the culprit re-arrested, the initial failure cast doubt on the ability of the police force to effectively deliver its mandate (MoGLSD, 2008).

Besides, budgetary and logistical constraints continue to cripple the police's ability to follow up and investigate suspected cases.

\footnotetext{
${ }^{2}$ This was through public information campaigns targeting traditional healers association, religious leaders, policy makers, schools, the Police and other stakeholders.
} 
Additionally, the poor relations between the police and communities hamper investigations. For example, Bukuluki (2009) noted that there is public mistrust about the police's commitment to investigate crimes, and that individuals are unwilling to cooperate with police in provision of information due to fear of reprisal from those who are suspected of engaging in child sacrifice. Police is suspected to collude with suspects of human sacrifice. Public mistrust was demonstrated during the trial of businessman Godfrey Kato Kajubi who was accused of the murder of Joseph Kasirye.

The news media reported that there were complaints that the suspect was being given preferential treatment. The police was perceived as being biased and partial. These accusations prompted the minister of internal affairs to make a statement in defense of police action (New Vision, 2009). Furthermore, Fellows (2013) indicated that the police in addition to being weak in documenting all cases of child sacrifice and mutilation, it intimidates and arrests informants. This prevents people from reporting cases of child sacrifice for fear of being victimized.

Uganda has not registered great success with regard to prosecution and conviction of child sacrifice suspects. In 2009, only 54 out of the 125 suspects who were arrested in connection with human sacrifice were produced in court. These were charged with various offenses ranging from murder abduction, kidnap, selling of children and practicing witchcraft ${ }^{3}$. Although an action plan has been developed, its effectiveness will depend on how it will be implemented. Uganda has a reputation of putting a great deal of attention on developing plans and policies and less on their execution. It is not clear whether the Ministry of Gender, Labour, and Social Development considered the fiscal implications of this plan.

Moreover, though the Prevention of Trafficking in Persons Act was welcomed as a breakthrough that provided for protection of children against child sacrifice, delays in implementation of the act have led to disappointment. The regulations to effect implementation are not yet in place. Presently, there is no policy to regulate the actions of traditional healers who are often blamed for child sacrifice.

The Uganda National Culture Policy (2006) gives the responsibility to develop and disseminate minimum traditional health service delivery standards, guidelines and indicators to the Ministry of Health. However, the health ministry has not actualized this mandate. Moreover, it is not known whether the ministry of health has the capacity to regulate traditional healers. The police identified that lack of a clear policy on the conduct and operations of traditional healers as a hindrance to investigation of cases ${ }^{4}$. The NGO coalition against Child Sacrifice continues to lobby for the enactment of a law to regulate the work of traditional healers and repeal the obsolete Witchcraft Act of 1957 but government seems to be dragging its feet.

The documentation and reporting of child sacrifice cases is still weak due to the fact that the affected poor families lack the means and patience to navigate the processes involved recording statements with the police, hiring lawyers to follow up the cases, travelling from home to meetings with the lawyers, and later to courts for each hearing. It is highly likely that current estimates of the magnitude of child sacrifice are inaccurate.

The arrest and intimidation of informers also precludes communities from reporting cases of child sacrifice and mutilation.

\footnotetext{
${ }^{3}$ Binoga Moses (2010) Human Sacrifice Overview Report for the Year 2009

${ }^{4}$ Binoga Moses (2010) Human Sacrifice Overview Report for the Year 2009
} 


\section{CONCLUSION AND RECOMMENDATIONS}

Data reviewed in this article shows that both government and civil society organizations responded swiftly to the growing problem of child sacrifice. However, most of the interventions were short-term in nature and the momentum seems to have waned. Most of the structural drivers of child sacrifice - poverty, unemployment, food insecurity, lack of a regulatory framework for traditional healers, and inadequate mechanisms for child protection at the community and family levels, and socio-cultural beliefs and practices are still present. Though SCORE and SUNRISE projects attempt to address some of these issues, if not well guided they may not adequately address the problem of child sacrifice. Moreover, these projects are not targeting all the rural districts with poor households that are likely to be affected by child sacrifice as the literature suggests. We therefore recommended that the Ministry of Gender, Labour and Social Development should ensure that current and future projects specifically focus on and address child sacrifice in the target districts.

The weaknesses in the regulatory framework, particular enacting the law sanctioning the work of traditional healers need to be given priority in order to minimize cases of witch doctors pausing as traditional healers. The police needs to be adequately facilitated to investigate, document, and fulfill its mandate. Government and civil society organizations need to develop mechanisms for ensuring that the poor have access to lawyers to handle cases of child sacrifice. The police instead of arresting and intimidating informers, it should work with them to identify and apprehend culprits.

Table 1. Instiututions and the various child sacrifice interventions undertaken.

\begin{tabular}{|c|c|c|c|c|c|c|c|c|}
\hline \multirow[b]{2}{*}{ Institution } & \multicolumn{8}{|c|}{ Types of Interventions } \\
\hline & 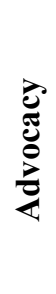 & 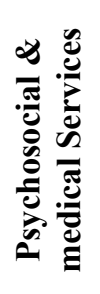 & 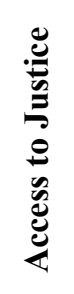 & 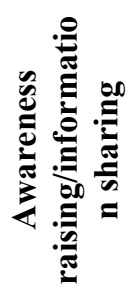 & 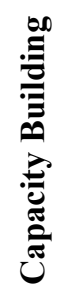 & 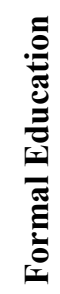 & 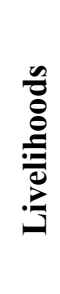 & 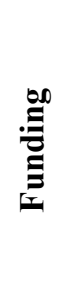 \\
\hline $\begin{array}{l}\text { THETA ( Traditional } \\
\text { and Modern Health } \\
\text { Practitioners together } \\
\text { against AIDS and Other } \\
\text { Diseases) }\end{array}$ & & & & $\sqrt{ }$ & $\sqrt{ }$ & & & \\
\hline $\begin{array}{c}\text { PROMETRA } \\
\text { (Promotion of } \\
\text { Traditional Medicine in } \\
\text { Uganda) } \\
\end{array}$ & & & & $\sqrt{ }$ & $\sqrt{ }$ & & & \\
\hline $\begin{array}{c}\text { Inter Religious Council } \\
\text { of Uganda }\end{array}$ & $\sqrt{ }$ & $\sqrt{ }$ & & $\sqrt{ }$ & & & & \\
\hline $\begin{array}{l}\text { Uganda Human Rights } \\
\text { Commission }\end{array}$ & $\sqrt{ }$ & & $\sqrt{ }$ & $\sqrt{ }$ & & & & \\
\hline UNICEF & $\sqrt{ }$ & & $\sqrt{ }$ & & $\sqrt{ }$ & & & $\sqrt{ }$ \\
\hline
\end{tabular}




\begin{tabular}{|c|c|c|c|c|c|c|c|c|}
\hline Uganda Police Force & & & $\sqrt{ }$ & $\sqrt{ }$ & $\sqrt{ }$ & & & \\
\hline $\begin{array}{c}\text { African Network for } \\
\text { Prevention and } \\
\text { Protection Against Child } \\
\text { Abuse and Neglect } \\
\text { (ANPPCAN) }\end{array}$ & $\sqrt{ }$ & $\sqrt{ }$ & $\sqrt{ }$ & $\sqrt{ }$ & $\sqrt{ }$ & $\sqrt{ }$ & $\sqrt{ }$ & \\
\hline World Vision Uganda & $\sqrt{ }$ & $\sqrt{ }$ & $\sqrt{ }$ & $\sqrt{ }$ & $\sqrt{ }$ & & & \\
\hline $\begin{array}{l}\text { Save the children } \\
\text { Uganda }\end{array}$ & $\sqrt{ }$ & & & $\sqrt{ }$ & & & & \\
\hline $\begin{array}{c}\text { Save Street Children } \\
\text { Uganda }\end{array}$ & $\sqrt{ }$ & & & $\sqrt{ }$ & & & & \\
\hline $\begin{array}{l}\text { Action for the Rights of } \\
\text { Children }\end{array}$ & $\sqrt{ }$ & & & $\sqrt{ }$ & & & & \\
\hline $\begin{array}{c}\text { Gideon Foundation } \\
\text { Against Child Sacrifice }\end{array}$ & $\sqrt{ }$ & & & $\sqrt{ }$ & & & & \\
\hline Joy for Children & $\sqrt{ }$ & & & & & & & \\
\hline $\begin{array}{c}\text { Human Rights Network } \\
\text { (HURINET) }\end{array}$ & $\sqrt{ }$ & & & & & & & \\
\hline $\begin{array}{c}\text { Federation of } \\
\text { International Women } \\
\text { Lawyers (FIDA } \\
\text { Uganda) } \\
\end{array}$ & $\sqrt{ }$ & & & & & & & \\
\hline $\begin{array}{c}\text { Plan International } \\
\text { Uganda }\end{array}$ & $\sqrt{ }$ & $\sqrt{ }$ & & $\sqrt{ }$ & & & & \\
\hline $\begin{array}{l}\text { Budukiro Child } \\
\text { Foundation }\end{array}$ & $\sqrt{ }$ & & & $\sqrt{ }$ & & & & \\
\hline $\begin{array}{l}\text { Media ( Electronic\& } \\
\text { print) }\end{array}$ & $\sqrt{ }$ & & & $\sqrt{ }$ & $\sqrt{ }$ & & & \\
\hline Lively Minds & $\sqrt{ }$ & $\sqrt{ }$ & & $\sqrt{ }$ & $\sqrt{ }$ & & & \\
\hline Safe World for Women & $\sqrt{ }$ & $\sqrt{ }$ & & $\sqrt{ }$ & & & & \\
\hline $\begin{array}{l}\text { United States } \\
\text { Government }\end{array}$ & & & & & $\sqrt{ }$ & & & $\sqrt{ }$ \\
\hline $\begin{array}{l}\text { Uganda Law Society } \\
\text { Legal Aid Project }\end{array}$ & $\sqrt{ }$ & & $\sqrt{ }$ & & & & & \\
\hline $\begin{array}{l}\text { Kyampisi Child Care } \\
\text { Ministries \& Jubilee } \\
\text { Campaign }\end{array}$ & $\sqrt{ }$ & $\sqrt{ }$ & $\sqrt{ }$ & $\sqrt{ }$ & & & $\sqrt{ }$ & \\
\hline
\end{tabular}




\section{References}

[1] Annie K., Uganda fights rise in child sacrifice: Witch doctors and organ traffickers blamed as children of the poor are seized for ritual murders; The Observer, London, UK, (2009) 39.

[2] Anonymous, USA equips Uganda police to fight human trafficking, child "sacrifice": BBC Monitoring Africa; London, June 12 2009. Retrieved from http:/www.accessmylibrary.com/coms2/summary_0286-38063809_ITM

[3] ANPPCAN, Campaign against Human Sacrifice: An Executive Summary, 2009.

[4] Ayre P., Child protection and the media: Lessons from the last three decades, British Journal of Social Work 31 (2001) 887-901.

[5] Bells, The Business of Child Sacrifice and Ritual Murders, 2011. Retrieved February 7 , 2012, from SciForums.com: http://www.sciforums.com/The-Business-of-Child-Sacrificeand-Ritual-Murders-t-110474.html

[6] Bukuluki P., Rapid assessment of Child Sacrifice in Uganda: Developing a National Action Plan to address the Problem of Child Sacrifice; Kampala: Ministry of Gender, Labour, and Social Development, 2009.

[7] Caplan P., 'Child sacrifice' in Uganda?: The BBC; 'witch doctors' and anthropologists, Anthropology Today 26(2) (2010) 4-7.

[8] Coalition against Child Sacrifice in Uganda, Press Release; $8^{\text {th }}$ February 2010.

[9] Fellow S., Child Sacrifice and the Mutilation of children in Uganda, 2013. Retrieved from http://www.humaneafrica.org/images/reports/Child\%20sacrifice\%20and\%20the\%20mutil ation $\% 20$ of $\% 20$ children $\% 20$ in $\% 20$ Uganda $\% 202$.pdf

[10] Jubilee Campaign and Kyampisi Child Care Ministries, Report on Child Sacrifice in Uganda: 2011. Retrieved on April 30, 2012 from http://www.jubileecampaign.co.uk/documents/child-sacrifice-report.pdf

[11] La Fontaine J., The extent and nature of organized and ritual abuse: Research findings; London: HMSO, 1994.

[12] Nkhonjera P., Leaders must focus on preventing child sacrifice, 2009. New Vision (Kampala). Retrieved on December 3, 2011 from http://www.newvision.co.ug/D/9/35/695432

[13] Nsubuga R., The Spiritual Rationale behind Human Sacrifice and The Search for Wealth in Uganda, (undated).

[14] Okwori J.Z., A dramatized society: representing rituals of human sacrifice as efficacious action in Nigerian home-video movies, Journal of African Cultural Studies 16(1) (2003) $7-23$.

[15] Ranger T., Scotland Yard in the bush: Medicine murders; child witches and the construction of the occult: A Literature Review Africa 77(2) (2007) 272-283.

[15] Retrak, Child Sacrifice in Uganda, 2011. Retrieved from http://www.retrak.org/uploaded/Child\%20Sacrifice\%20Uganda,\%20Oct\%202011.pdf 
[16] Safe World for Women, Working to Abolish Child Sacrifice in Uganda, (undated). Retrieved february 7, 2012, from http://www.asafeworldforwomen.org: http://www.asafeworldforwomen.org/partners-in-africa/partners-inuganda/eaco/studies.html

[17] Saunders B. \& Goddard C., The role of Mass Media in Facilitating Community Education and Child abuse Prevention Strategies, 2002. Retrieved on November 23, 2011 from http://www.aifs.gov.au/nch/pubs/issues/issues16/issues16.html

[18] Straziuso J., Human sacrifice on the rise in Uganda: 'Laws in limbo' blamed as children fall prey to ruthless witch doctors; Associated Press: Toronto Star; Toronto, Ontario, (2010) 9 . 